\title{
Translation Efficiency of Chinese Official Slogans in the Light of Skopostheorie
}

\author{
DOU Wei-lin \\ University of International Business and Economics
}

\author{
ZHU Ping \\ Nanhu College of Jiaxing University
}

\begin{abstract}
Proper translation of Chinese official slogans is of vital importance to foreign publicity of the People's Republic of China. This paper reports a study of the efficiency of existing translations of Chinese official slogans in the light of Skopostheorie, which redefines the concept of translation to be a purpose-guiding activity. Gauged through questionnaires circulated among and follow-up interviews of English native speakers, the survey reveals that although a majority of the slogans make sense to them, certain misunderstandings still exist due to ideological, cultural, and linguistic differences. It also provides guidance and suggestions for translating Chinese official slogans.
\end{abstract}

Keywords: official slogans, translation efficiency, English readers, Skopostheorie

\section{Introduction}

English translations of Chinese official slogans play a crucial role in foreign relations. Good translations of these slogans can promote foreigners' understanding of China and help to project a developing and progressive national image to the world, while poor renderings add to the barriers between the East and the West and can even affect normal international relations. For instance, the original English translation of the 2008 Beijing Olympics slogan was "New Beijing, New Olympics", which caused some consternation among members of the International Olympic Committee (YU, 2002). Did it mean that Beijing would remake the Olympic rules or set up a new Olympic organization? Actually, the Chinese word Xin (new) lays more emphasis on a new atmosphere, whereas the English word "new" carries the meaning of "updating". Accordingly, the English translation of the slogan was changed to "New Beijing, Great Olympics”.

Many a scholar has adopted the acceptability of translations as the yardstick for measuring their quality (LUO, 1999; SHEN \& LIU, 2000; WU, 1998; YANG, 2006; YU, 2002; ZHU, 2006). Thus far, however, few scholars have done any practical research on the question of acceptability. Through questionnaires and follow-up interviews, the present study analyzes both the efficiency of the translations of Chinese official slogans and the reasons why some translations have caused misunderstanding or confusion, thereby, providing basis for improving slogan translations.

What makes this research important is that the translation of official slogans has not been systematically touched upon by Skopostheorie in its application. While the areas of translator training, literature, medicine, and 
advertising in China have been studied by scholars at home and abroad, the translation of Chinese official slogans has caught little attention in their work of probing into the practice of the theory. It is hoped that with the application of Skopostheorie in the study of the translation of Chinese official slogans in this research, researchers on translation theories may get a slightly better understanding of Skopostheorie and, more importantly, translators of slogans will have an important guiding theory to follow in their practice.

\section{Literature Review}

\section{Skopostheorie as the Chinese-English Translation Standards of Chinese Official Slogans}

According to Skopostheorie, translation strategies are determined by the purpose (Skopos) of the target texts. In the translation process, it is the Skopos of translation that matters. Different purposes and functions may require different translation strategies. When choosing appropriate translation strategies, translators should take the purposes and functions of the target texts into consideration. It is target-oriented in nature.

With the intended function of the target text as its top principle, Skopostheorie places translation in its socio-culture context, which stresses functionality and includes the interplay between translators and the institution which initiates it, thus offering a more objective and dynamic perspective.

The translating of Chinese official slogans aims at achieving their foreign publicity functions, that is, making more and more countries or peoples understand China and its policies. Also, the quality of translation directly determines the effect of translation and influences target readers' understanding of China. Therefore, to make these slogans achieve their functions becomes a vital element in evaluating the quality of the translations. To be specific, the translations of Chinese official slogans should follow three rules: first, faithfulness; second, comprehensiveness; and finally, linguistic accuracy and modification.

\section{Basic Concepts and Rules of the Skopostheorie}

Since the 1970s, there emerged a new school in Germany which viewed translation in a broader perspective of human communication. This is known as the functionalist approach to translation, whose representative proponents are Katharina Reiss, Hans Vermeer, Justa Holz-Manttari, and Christiane Nord. Functionalism is a broad term for various theories that approach translation, among which Vermeer's Skopostheorie has played a major role in the development of the trend (Nord, 2002, pp. 12-25).

In Skopostheorie, the concept of culture is very important. In the Skopostheorie, translation is looked on as "offering information to members of one culture in their language (the target language and culture) about information originally offered in another language within another culture (the source language and culture)" (Malmkjear, 2004, p. 64). This information-offering view on translation adds to the characteristics of translation as not only a linguistic, but also a "cultural-transcending process” (Malmkjear, 2004, p. 64). Further, Nord points out that translation takes place in concrete, definable situations that involve members of different cultures (Nord, 2002, p. 124), which suggests that translation is an intercultural action.

Thus, they put forward three rules of Skopostheorie as the following:

Firstly, the "Skopos Rule”. The top-ranking rule for any translation is the "Skopos Rule”, what Reiss and Vermeer (1984) described as "the end justifies the means” (p. 123). Skopos is a Greek word for "purpose”. According to Skopostheorie, the prime principle determining any translation process is the purpose (Skopos) of the overall translational action (Reiss \& Vermeer, 1984, p. 11). Nord divided the aims/purposes of 
translating into three groups: the general purpose aimed at by the translators in the translation process (perhaps to "earn a living"); the communicative purpose aimed at by the target text in the target situation (perhaps "to instruct the reader"), and the purpose aimed at by a particular translation strategy or procedure. The Skopos usually refers to the purpose of the target text (Vermeer, 1989, p. 12). In the process of translational action, the initiator decides the communicative purpose.

Secondly, the "Fidelity Rule". An important part of Skopostheorie is intertexual coherence vs. intratexual coherence. What the translators can do, and should do, is to produce a text that is at least likely to be meaningful to target-culture receivers. In Vermeer's terms, the target text should conform to the standard of "intratextual coherence” (Reiss \& Vermeer, 1984, p. 76). A communicative interaction can only be regarded as successful if the receivers interpret it as being sufficiently coherent with their situation.

However, since a translation is an offer of information about a preceding offer of information, it is expected to bear some kind of relationship with the corresponding source text. Vermeer calls this relationship "intertextual coherence" or "fidelity". This is postulated as a further principle, referred to as the "Fidelity Rule" (Reiss \& Vermeer, 1984, p. 92). Again, as in the case of the "Skopos Rule", the important point is that intertextual coherence should exist between source and target text, while the form it takes depends both on the translators' interpretation of the source text and on the translation Skopos (Nord, 2002, p. 132). One possible kind of intertextual coherence could be a maximally faithful imitation of the source text. As Vermeer points out, this may be the form expected in literary translation (Nord, 2002, p. 132).

Thirdly, the "Loyalty Principle". To eliminate the misunderstanding that Skopos theory only emphasizes target language and neglects the importance of source language and to make the Skopostheorie more acceptable, Nord (2002) put forward the "Loyalty Principle". She maintained that there should be a moral responsibility on the part of the translators who owe the readers an explanation of what they have done in the translation work as well as the reason. On the other hand, the translators should respect the source-text producer and coordinate the translation purpose with the source-text producer's intention.

"Loyalty" commits the translators bilaterally to the source and the target sides. The "Loyalty Principle" thus adds two important qualities to the Functional Approach. Since it obliges the translators to take account of the difference between culture-specific concepts of translation prevailing in the two cultures involved in the translation process, it turns Skopostheorie into an anti-universalist model; and since it induces the translators to respect the sender's individual communicative intentions as far as they can be elicited, it reduces the prescriptiveness of radical functionalism.

Thus, Nord (2002) proposed that: "Let your translation decisions be guided by the function you want to achieve by means of your translation” (p. 86), which she thought has been found to be quite a useful rule in the translation process. What really matters here is the Skopos. Only whether the Skopos is realized or not determines the successfulness of a target text.

\section{Study of Chinese Slogan Translation}

Official slogans present the stances of governments on international and domestic issues, and they can influence the social and economic life of a community. Although they differ in their content, which ranges from economic affairs to agriculture, and from technological and military matters to foreign affairs, official slogans are typically written on behalf of a certain class (or a certain group) and serve a certain political purpose. Furthermore, 
as a way of expressing a country's opinion or will, slogans mirror a nation's historical features and distinctive cultural background. Chinese official slogans are no exception.

The policy of opening up to the outside world practiced since the late 1970s has given rise to greater communication between China and other countries in many fields. A lot of international conferences, forums, meetings, and festivals are held in China. An increasing number of foreigners come to China either on business or as tourists. Consequently, expanded communication with the outside world has added to the necessity of translating official slogans into English as a means of foreign publicity and communication.

According to statistics, 70\% of China's communication with foreign countries is done in English (F. G. LIU, 1995, p. 44), a vast amount of which is in journals where information in China is rendered into English before it is transmitted to the foreign readers. Therefore, English translation of Chinese official slogans has an undeniable importance in enabling more and more foreigners to understand China.

Due to the practical use of slogans in society nowadays, research on the translations of Chinese slogans has become an academic growth industry. Quite a number of scholars have been studying it, and their research results have been published in many reputable Chinese journals.

The earliest attention was paid to this field by LU Zu-ben, who claimed the importance of slogan translation in foreign publicity and pointed out four major problems in the Chinese-English translations of Chinese slogans (LU, 1994, pp. 51-56). During the late 1990s, WU Wei-xiong, DING Ming-an, and LUO Tian-fa made continuous efforts in their research on the Chinese slogan translation. WU classified three kinds of common faults, namely word-for-word translation, misinterpretation, and random translation, and discussed the features of Chinese slogans from the syntax perspective and their impact on Chinese-English translation. Finally, he emphasized that slogan translation should take into account the cultural background of the readers and make sense to them (WU, 1998, pp. 35-38). Through a case study, DING's (1999, p. 27) conclusion was that in Chinese-English slogan translation, infinitives "to be” and gerunds “-ing” formats should be avoided.

To strengthen WU's conclusion, SHEN and LIU (2000) put forward the principle of KISS (Keep It Short and Sweet) in terms of slogan writing and translating, and held that slogans—-whatever languages they use-should follow the rules of being succinct and eye-catching, and take into full consideration the readers' acceptability. Six years after the publication of SHEN and LIU's essay, ZHU (2006) reiterated the importance of acceptability of English translations of Chinese slogans from the angles of semantics, syntax, rhyming and cultural connotation.

TANG (2000) probed the similarities and differences in stylistic and linguistic characteristics between Chinese and English slogans, and held that the main causes of the differences lie in the divergent cultural backgrounds and modes of thinking between the Chinese and English-speaking peoples. She put forth two principles for the translation of slogans: first, faithfulness to the linguistic and cultural habits of English-speaking people; second, accuracy and conciseness in the information transference.

WU and ZHANG (2007) summarized the features and classification of slogans and also revealed several problems in the Chinese-English translation of slogans, pointing out three techniques of translating: literal translation; proper addition and omission; and conversion and restructuring.

More essays have been published in the new millennium on the translation of Chinese slogans. WU (2006) updated his 1998 essay by emphasizing that the verse of translation should be striking, impressive, concise, and 
powerful in terms of sentence style and sound, as well as fully receivable in terms of cultural background, psychological factors, and syntax style so as to produce situational effects pleasing to the ears, the eyes, and the mind. Some scholars have tried to explore the Chinese-English translation of slogans by employing translation theories as their yardstick. Based on the Skopos theory, YU (2002) claimed that the translating of Chinese slogans was a purposeful activity and therefore translators should fully consider the functions of different types of slogans when choosing translation strategies. YU then divided Chinese slogans into five types-political, advocating, announcing, ceremonial, and advertising — and raised different translation strategies for each. SHI (2004) made an attempt to analyze the translating of Chinese slogans from Nida's dynamic equivalence standard, and maintained that there were three angles to evaluate the standard: the language, the culture, and the translation process. Some essays discuss the Chinese slogans from a more micro-structural perspective. CHEN (2007) observed that the improvement of Chinese-English translation quality of slogans should go a step further than correcting "low-level" mistakes such as spelling and grammar. The core of the problem is the pragmatics and rhetorical differences of Chinese and English. Only with a thorough understanding of this can proper adjustment be made in the process of translation and fundamental effects be achieved on the translation quality. MAO (2004) pointed out that "China English" inevitably exists in the translation of special terms in current affairs, and it is quite different from "Chinese English” or "Chinglish”. YANG (2006) explored the translation of political economic words and phrases with Chinese characteristics and believed that the correctness of translation of them will directly result in the foreigners' real understanding of China's policy. FEI (2006) made an analysis on newly coined English words from social and cultural perspectives, focusing on the influence from technology, politics, economy, and daily life. WU and ZHANG (2007) probed the differences of Chinese and American political slogans from the perspective of the thinking style of the two peoples.

Unfortunately, similar studies carried out in English-speaking countries are quite limited. Few Western scholars have chosen Chinese official slogans as their subject of research. The only essay the present authors have found is one entitled "An Ideological/Cultural Analysis of Political Slogans in Communist China”, which examines the use of political slogans in China from the early 1960s to the late 1980s. Since the study involves ideology, a quite sensitive topic, this essay does not provide much insight to the study of this thesis.

All the works mentioned above have made noteworthy contributions to the study of Chinese slogans. However, there are three main limitations compared with the authors' present research in this thesis. First, due to limited space, none of the published essays has presented a thorough review of the theoretical basis of Chinese-English slogan translation. Second, all of the results are based on qualitative rather than quantitative research. Some conclusions are thus on sporadic impressions or experiences in translating. Third, many of these works offer only a general introduction to Chinese slogans instead of focusing on the more specific field of official slogans. Some of them discuss only one category of slogans, such as those in tourism or advertising.

The present study intends to fill some of the gaps in the scholarly literature by adopting a new approach, namely conducting a questionnaire survey on the efficiency of the Chinese official slogan translations. Since the efficiency of translated slogans, or their meaningfulness to target-culture receivers, is of great importance in the light of Skopostheorie, the authors will comment on their findings and offer suggestions regarding the translation strategies of Chinese official slogans. 


\section{Research Methodology}

A survey was made to study the efficiency of existing translations of the Chinese official slogans in the light of Skopostheorie.

\section{Source of Statistics}

The official slogans under consideration cover a span of 13 years, i.e., since contemporary Chinese foreign publicity began to thrive in the late 1970s, when China adopted policies of reform and opening up to the world. The principal primary sources are a column about important slogans in the history of the CPC (Communist Party of China) in the online People's Daily (retrieved from http://cpc.people.com.cn/GB/64162/64170/index.html), reports on the National People's Congress and the Congress of CPC Party Representatives, and People's Daily. These slogans have become established through repeated use and are deeply rooted in people's minds. The English translations considered are from China Daily, the English version of People's Daily, various academic journals and the Internet. Covering political, economic, social, and diplomatic topics, they embody certain characteristics and tendencies in the development of Chinese society during the past three decades.

\section{Subjects}

The respondents were all native speakers of English and included Englishmen, Americans, and Australians. Eighty-six questionnaires were distributed in native English speakers by email, of which 51 valid ones were returned. Thirty-two were male and 19 female. Their ages ranged from 23 to 64 years with an average age of 35 . They were engaged in various careers, such as college professor, newspaper editor, company manager, web designer, and student. Forty-four (86\%) had visited China and 38 (75\%) were working or studying in China at the time of the survey. Follow-up interviewees include professors and students of Cambridge University, employees and officials of English enterprises, as well as the authors' foreign friends.

\section{Instruments}

For this study, the methods of questionnaire and follow-up interviews were adopted. The former was the main approach, while the latter served to clarify some questions which emerged when the questionnaires were analyzed. The questionnaire was designed by the authors and consisted of two parts. The first of these was 36 translated Chinese official slogans, each followed by this statement: "This expression is clear to me. Yes __ No __”. Respondents who answered "No" were asked to explain briefly the reason why they found it difficult to understand the slogan. Since these translations were fairly uniform, they were classified into the first part. Here is Example (1):

Example (1) S1 (Slogan 1): The Four Cardinal Principles (this slogan refers to adherence to the socialist road, the people's democratic dictatorship, the leadership of the CPC, and Marxism-Leninism and MAO Ze-dong's thought).

This expression is clear to me.

Yes

No __ (if no, please briefly explain why)

The second part encompassed 14 groups of Chinese official slogans. For each of these, two or more translations were given. These were included in the second rather than the first part of the questionnaire, because different English versions of these slogans coexist. Subjects were asked to indicate their preferences and briefly explain why they preferred them. Take the first pair as an example (see Example (2)): 
Example (2) S37 (a) One family, one child.

(b) It is good to have only one child.

I prefer because

There was a background information section at the end of the questionnaire which included questions about the respondent's gender, age, whether he/she was studying or working at the moment, and so on. The last question was posed to see how familiar the subjects were with contemporary Chinese culture. They were asked to rank this on a scale from 0 ("totally unfamiliar") to 3 ("very familiar"). A subject's answer of "totally unfamiliar" was equated with a numerical value of 0 , while ("somewhat unfamiliar") was 1 , "somewhat familiar" was 2, and "very familiar" was 3 . This section was also intended to get other basic information about the respondents. The authors assume that the degree of familiarity with Chinese culture may have influenced the subjects' answers to the questionnaire. Data were input and processed on a computer with Excel and SPSS (Statistical Product and Service Solutions).

\section{Results and Discussion of the Survey}

\section{Findings of Part 1}

Responses to all the items in Part 1 are reported in Table 1. All percentages refer to the number of subjects who understood or did not understand the statement in each item.

Table 1

Percentages of People Selecting "Yes" and "No" for Each Slogan

\begin{tabular}{|c|c|c|c|}
\hline $\begin{array}{l}\text { Slogan serial } \\
\text { number }\end{array}$ & Translations of slogan & “Yes" (\%) & "No" (\%) \\
\hline$\overline{\mathrm{S} 1}$ & The Four Cardinal Principles & 60.8 & 39.2 \\
\hline S2 & Four Modernizations & 64.7 & 35.3 \\
\hline S3 & Seeking truth from facts, liberation of mind & 58.8 & 41.2 \\
\hline S4 & Reform and opening up & 82.4 & 17.6 \\
\hline S5 & $\begin{array}{l}\text { Citizens with lofty ideals, moral integrity, better education and good sense of } \\
\text { discipline }\end{array}$ & 70.6 & 29.4 \\
\hline S6 & The movement of "five stresses, four points of beauty and three loves" & 29.4 & 70.6 \\
\hline S7 & Promote the construction of spiritual and material civilization & 78.4 & 21.6 \\
\hline S8 & One country, two systems & 70.6 & 29.4 \\
\hline S9 & Time is money, efficiency is life. & 78.4 & 21.6 \\
\hline S10 & Socialist market economy & 82.4 & 17.6 \\
\hline S11 & Seize the chance and develop ourselves & 100.0 & 0.0 \\
\hline S12 & One central task and two basic points & 60.8 & 39.2 \\
\hline S13 & Poverty cannot be socialism & 70.6 & 29.4 \\
\hline S14 & Primary stage of socialism & 60.8 & 39.2 \\
\hline S15 & Three-step development strategy & 78.4 & 21.6 \\
\hline S16 & Science and technology constitute the primary productive force. & 88.2 & 11.8 \\
\hline S17 & Building socialism with Chinese characteristics & 82.4 & 17.6 \\
\hline S18 & Three Favorables & 33.3 & 66.7 \\
\hline S19 & $\begin{array}{l}\text { Grasp the opportunity, deepen the reform, expand openness, promote development, } \\
\text { and keep stability }\end{array}$ & 82.4 & 17.6 \\
\hline S20 & $\begin{array}{l}\text { Arming people with scientific theory, guiding people with correct media, figuring } \\
\text { people with high-minded spirit, inspiring people with excellent works }\end{array}$ & 66.7 & 33.3 \\
\hline
\end{tabular}


(Table 1 continued)

\begin{tabular}{|c|c|c|c|}
\hline $\begin{array}{l}\text { Slogan serial } \\
\text { number }\end{array}$ & Translations of slogan & "Yes" (\%) & "No" (\%) \\
\hline$\overline{\mathrm{S} 21}$ & $\begin{array}{l}\text { Liberation of mind, seeking facts from truth, doing solid work, development and } \\
\text { making progress }\end{array}$ & 33.3 & 66.7 \\
\hline S22 & Integrating with the world & 88.2 & 11.8 \\
\hline S23 & The intensive education in the need to stress study, political awareness and integrity & 56.9 & 43.1 \\
\hline S24 & Not to devalue the RMB & 82.4 & 17.6 \\
\hline S25 & Three represents & 33.3 & 66.7 \\
\hline S26 & $\begin{array}{l}\text { Environmental-friendly Olympics, culture-enriched Olympics, and } \\
\text { Technology-empowered Olympics }\end{array}$ & 82.4 & 17.6 \\
\hline S27 & Keeping up with the times & 100.0 & 0.0 \\
\hline S28 & To build a well-off society in an all-round way & 84.3 & 15.7 \\
\hline S29 & Peaceful rise & 64.7 & 35.3 \\
\hline S30 & Power for the people, interest by the people, sentiment towards the people & 29.4 & 70.6 \\
\hline S31 & Building a party for the interests of the people and assuming power for the people & 90.2 & 11.8 \\
\hline S32 & To build a socialist harmonious society & 82.4 & 17.6 \\
\hline S33 & To build a harmonious world & 88.2 & 11.8 \\
\hline S34 & One World, One Dream & 100.0 & 0.0 \\
\hline S35 & Building a new socialist countryside & 80.4 & 19.6 \\
\hline S36 & Energy saving/conservation and emission reduction & 100.0 & 0.0 \\
\hline
\end{tabular}

The statistics show that eight slogans (22.2\% of the total) received over $85 \%$ "Yes" responses. The following four slogans were best understood by the respondents: "Seize the chance and develop ourselves" (S11), "Keeping up with the times" (S27), "One World, One Dream” (S34), and "Energy saving/conservation and emission reduction" (S36). On the other hand, five slogans (13.9\% of the total) had over 50\% answering "No"; that is to say, more than half of the subjects failed to understand nearly $14 \%$ of the slogans. The translations most confusing to the native speakers were the following three: "The movement of 'five stresses, four points of beauty and three loves'” (S6), "Liberation of mind, seeking facts from truth, doing solid work, development and making progress” (S21), and “Three Represents” (S25).

\section{Findings of Part 2}

Responses to all the items in Part 2 are reported in Table 2, which shows most subjects' preference of translation in each group.

Table 2

Percentages of Choosing Each Translation

\begin{tabular}{|c|c|c|}
\hline $\begin{array}{l}\text { Slogan serial } \\
\text { number }\end{array}$ & Translations of the slogan & Preferences (\%) \\
\hline \multirow[t]{2}{*}{ S37 } & (1) One family, one child & 68.6 \\
\hline & (2) It is good to have only one child. & 31.4 \\
\hline \multirow[t]{2}{*}{ S38 } & $\begin{array}{l}\text { (1) The ranks of the cadres become more revolutionary, younger in average age, } \\
\text { better-educated, and more professionally competent. }\end{array}$ & 13.7 \\
\hline & (2) Cadres are more revolutionary, younger, better-educated, and more professional. & 86.3 \\
\hline \multirow[t]{3}{*}{ S39 } & (1) Our education should face the modernization program, the world, and the future & 13.7 \\
\hline & (2) Gear education to the needs of modernization, the world, and the future & 62.7 \\
\hline & (3) Orient education towards modernization, globlization, and future construction & 23.5 \\
\hline \multirow[t]{2}{*}{ S40 } & (1) Let some people get rich first & 31.4 \\
\hline & (2) Let a few get rich first & 68.6 \\
\hline
\end{tabular}


(Table 2 continued)

\begin{tabular}{|c|c|c|}
\hline $\begin{array}{l}\text { Slogan serial } \\
\text { number }\end{array}$ & Translations of the slogan & Preferences (\%) \\
\hline \multirow[t]{2}{*}{ S41 } & (1) Maintaining stability is of top priority & 80.4 \\
\hline & (2) Stability is a principle of overriding importance & 19.6 \\
\hline \multirow[t]{4}{*}{ S42 } & (1) Development is the only way & 19.6 \\
\hline & (2) Development is the top priority & 74.5 \\
\hline & (3) Development is the most essential criterion & 0.0 \\
\hline & (4) Development is the absolute principle & 5.8 \\
\hline \multirow[t]{2}{*}{ S43 } & (1) Revitalizing China through science and education & 80.4 \\
\hline & (2) National rejuvenation through science and education & 19.6 \\
\hline \multirow[t]{2}{*}{ S44 } & (1) Rule by law & 19.6 \\
\hline & (2) Rule of law & 80.4 \\
\hline \multirow[t]{2}{*}{ S45 } & (1) New Beijing, New Olympics & 37.2 \\
\hline & (2) New Beijing, Great Olympics & 62.7 \\
\hline \multirow[t]{2}{*}{$\overline{S 46}$} & (1) Rule of morality & 43.1 \\
\hline & (2) Rule of virtue & 56.9 \\
\hline \multirow[t]{2}{*}{ S47 } & (1) Two "Musts" & 13.7 \\
\hline & (2) Two Necessities & 62.7 \\
\hline \multirow[t]{3}{*}{ S48 } & (1) People-oriented & 25.5 \\
\hline & (2) People first & 56.9 \\
\hline & (3) “Putting people first” principle & 5.8 \\
\hline \multirow[t]{3}{*}{ S49 } & (1) To build an energy-saving society & 37.2 \\
\hline & (2) To build a conservation-oriented society & 43.1 \\
\hline & (3) To build an economized society & 5.8 \\
\hline \multirow[t]{2}{*}{ S50 } & (1) Eight Honors and Eight Disgraces & 37.2 \\
\hline & (2)Socialist concept of honor and disgrace—Eight Dos and Don'ts & 43.1 \\
\hline
\end{tabular}

Note. For various reasons, from groups 11 to 14, some of the subjects either did not make any choices, or they chose all of the given translations. Therefore, the sum for each of these groups does not add up to $100 \%$.

The reasons why the subjects preferred one of the translations in each group mainly consist of the following: For slogans made up of simple sentences (such as S37), it was "simpler”, "more colloquial”, "more eye-catching and more memorable”, etc.. For slogans comprising two or more parallel structures (such as Group 2), the reasons given were that they were "clear and consistent", "more active”, "more like modern English", and "sound more logical”. For slogans containing numbers (such as Group 4), the reasons stated were that they were "more specific" and "more precise”. Beginning a sentence with a verb "makes it more active than a noun”. For instance, some respondents thought that the second translation "Gear education to the needs of modernization, the world and the future" (S39) has a "good use of the verb 'gear”. It is much better than the first translation "Our education should face the modernization program, the world and the future", in which the word "face" has the meaning of "to overcome (a problem) by confronting boldly or bravely". For S43, some respondents thought that it made a "strong start" by using the verb structure "revitalizing".

The reasons why the subjects did not choose other translations were essentially the opposite, i.e., "too vague”, “do not conform to the English way of speaking”, "lack logical relations”, and so on.

\section{Correlation Analysis}

Respondents were asked to indicate the extent to which they were familiar with Chinese culture on a scale of 
0 to 3 (i.e., $0=$ totally unfamiliar and $3=$ very familiar). This was done to test the relationship between their degree of familiarity with Chinese culture and their understanding of the slogans.

Table 3 shows the descriptive statistics of the subjects' degree of familiarity with Chinese culture. For each subject, the percentage of his/her choosing "yes, the translation is clear to me" among all the 36 slogans is represented by $p$. For instance, if a respondent responded "yes” to 11 of the 36 translations, his/her $p$-value would be 0.31 . At the same time, his/her $f$-value could be 2 , which means that he/she was "somewhat familiar" with Chinese culture. If a respondent understood all of the 36 translations of slogans, his/her $p$-value would be 1.00.

Table 3

Descriptive Statistics of the Two Variables

\begin{tabular}{llllll}
\hline & $\mathrm{N}$ & Minimum & Maximum & Mean & Std. deviation \\
\hline$f$ & 51 & 0.00 & 3.00 & 1.5098 & 0.73137 \\
$p$ & 51 & 0.31 & 1.00 & 0.7211 & 0.16101 \\
Valid N (listwise) & 51 & & & & \\
\hline
\end{tabular}

In order to find out the relationship between the two variables, Pearson correlation analysis was conducted with SPSS. Table 4 shows that the correlation coefficient between the two variables is statistically significant, $r=0.80, p<0.001$. It indicates that the two variables are in positive relationship. In other words, the more familiar the subjects were with Chinese culture, the more likely they were to understand the translations.

Table 4

Correlation Analysis

\begin{tabular}{llcc}
\hline & Inferential statistics & $p$ & $f$ \\
\hline$p$ & Pearson correlation & 1 & $0.797\left(^{*}\right)$ \\
& Sig. (2-tailed) & & 0.000 \\
$\mathrm{~N}$ & 51 & 51 \\
$f$ & Pearson correlation & $0.797\left(^{*}\right)$ & 1 \\
& Sig. (2-tailed) & 0.000 & 51 \\
\hline
\end{tabular}

Note. ${ }^{*}$ Correlation is significant at the 0.01 level (2-tailed).

\section{Comments and Translation Strategies}

From the results of the survey and interviews, we find that foreigners' understanding of Chinese official slogans is primarily influenced by the extent to which these slogans are culturally-related, in other words, whether these slogans convey Chinese characteristics. The closer they are related to unique Chinese culture and ideas, the harder they are for foreigners to understand. The "misunderstanding caused by uniqueness" is first of all a product of ideological differences, and it also has to do with cultural differences. Last but not least, language itself constitutes a barrier to understanding. The following is a discourse analysis based on the three aspects, as well as corresponding solutions and suggestions.

\section{Ideological Differences and Corresponding Solutions}

The biggest factor that hinders understanding is the ideological differences. China and other English-speaking countries have different political systems and different ideologies, which make it difficult for 
native English speakers to fully understand some Chinese official slogans. For instance, many interviewers find it difficult to understand "Socialist market economy" (S10), "Building a socialist countryside" (S17), "Poverty cannot be socialism" (S13), and "One country, two systems" (S8), indicating that they are "not familiar with the politics of socialism". Some interviewers hold that slogans such as "Citizens with lofty ideals, moral integrity, better education and good sense of discipline" (S26), "Science and technology constitute the primary productive force" (S16), and "Promote the construction of spiritual and material civilization" (S7) are "two vague", "too abstract”, and "weird". The slogan "Arming people with scientific theory, guiding people with correct media, figuring people with high-minded spirit, inspiring people with excellent works" (S20) also causes perplexity. Some think that the term "correct media" is confusing, and wander whether this refers to "media censorship". Also it is really hard to judge what kind of media is "correct", let alone using this kind of media to "guide people". What is more, the word "spirit" is often associated with "religion", therefore attaching a religious consideration to the slogan. The slogan "seeking truth from facts, liberation of mind" (S3) causes bewilderment to the subjects, especially its second part. In Western people's view, "Liberation of mind" can be interpreted in multiple ways, such as finding religion, thinking independently, or any number of things. As far as the slogans "to build a socialist harmonious society" (S32) and "to build a harmonious world" (S33) are concerned, the word "harmonious" has a long historic background and connotation in Chinese culture. However, $17.6 \%$ and $11.8 \%$ of the respondents respectively find them hard to accept from Western points of view. Their reasons include "What about the competitiveness and conflict that are inevitable in progress?”.

In spite of inevitable ideological differences, the key is how to promote understanding by bridging the ideological gap with the help of translation. Through a careful study of the original slogans, translators should grasp their essence and connotations, then interpret them in ways that correspond with the linguistic features of the target language. Only in that way are the translated versions likely to be understood by native speakers of English. In other words, they can then fulfill the Skopos (purpose) of slogan translation.

In fact, any one with an understanding of translation will not always expect to find equivalent expressions in the target language. Consequently, translators often adopt liberal translation. Also called free translation, this is an alternative approach which is used mainly to convey the meaning and spirit of the original text without trying to reproduce its sentence patterns or figures of speech. This approach is most frequently adopted when it is impossible to do literal translation. In many cases, literal translation is not sufficient to produce good renditions of meaning.

As Chinese official slogans focus on the target readers and serve the purposes of better communication and understanding of Chinese policies, it is easier for us to understand the frequent employment of liberal strategies in Chinese official slogan translation. It is an effort to reproduce the functions of the original slogans to achieve the ultimate purpose of Chinese official slogan translation.

Unconfined by the slogans' literal meanings, the target readers can better understand the situation in China and thereby fulfill the purpose of translation. In other words, in order to avoid negative perceptions of the Chinese social system from reading the translations of slogans, what should first and foremost be taken into consideration is to convey their essential meaning. For example, the survey revealed an obvious negative implication in the slogan "Poverty cannot be Socialism” (S13). This version is a seemingly perfect literal translation, but it is only a 
translation of the form. Some respondents challenged the correctness of certain slogans by saying that "Poverty cannot be socialism" sounds "funny", because some countries or people "however choose poverty", and "Gandhi" is a case in point. Also, "the statement is too broad to be possible" (personal communication, September 9, 2008). If we manifest the implicit information of the slogan and translate it as: "Poverty is not a necessary evil of socialism”, such a revision would be less likely to distort native English speakers' negative perception of "socialism" and would make the world know more about China.

\section{Cultural Differences and Corresponding Solutions}

Other important factors affecting English native speakers' understanding are social and cultural differences. Lacking knowledge of China's unique traditional culture and its basic condition leads to many foreigners' failure to understand Chinese official slogans. For example, "It is good to have only one child" (S37), "imposes an opinion about having one child", and the immediate responses to the slogan are "Why?" or "is it bad to have more than one child?”, "Stability is a principle of overriding importance” (S41) may imply that there isn’t yet stability”. Some respondents think "Development is the only way" (S42) is false, because "there are many ways", and the use of the word "only" is too "abrupt”; by contrast, "Development is the most essential criterion" (S42) makes people "question the other criteria". Another interesting finding is that some slogans cause entirely different associations among the subjects. For instance, one respondent said that the slogan "Grasp the opportunity, deepen the reform, expand openness, promote development, and keep stability” sounded like a Yoga movement. Another said that "Liberation of mind, seeking facts from truth, doing solid work, development and making progress" reads like a school report, etc.. The percentage of people that do not like either translation of slogan 50 ("Eight Honors and Eight Disgraces; Socialist concept of honor and disgrace-Eight Dos and Don’ts”) rises to 20\%. One respondent said that the two translations were "too similar to Christian fundamentalism. Nothing is simple or merely reducible to eight parts in this world, and the Ten Commandments are also in need of updating” (personal communication, September 11, 2008). Another interesting comment is that "Westerners do not think in chengyu [A traditional Chinese expression which is characterized by four-letter set phrases], and the number eight is not special to us" (personal communication, September 11, 2008).

A careful study of the translated slogans shows that many of them are literal renditions. In the common understanding, literal translation strives "to keep the sentiments and style of the original” (Z. D. LIU, 1995, p. 57). Specifically, in much Chinese-English translation, English words chosen directly correspond to Chinese ones with little structure changed. In the translation of slogans, this method is commonly used in the slogans composed of parallel words, parallel word groups, and sentences if English versions can completely and clearly convey the information contained in the source texts. For example, "One country, two systems” (S8), "One central task and two basic points" (S12), and "Grasp the opportunity, deepen the reform, expand openness, promote development, and keep stability” (S19). Respectively, 70.6\%, 60.8\%, and 82.4\% of the respondents believed that these slogans made sense to them.

Therefore, if translators can find in the target language expressions that are completely or almost equivalent to those in the source language, literal translation is advisable. Functionalism does not exclude equivalence; what it holds on to is that equivalence is not a permanently valid principle. In Skopostheorie, equivalence means adequacy to a Skopos and requires that the target text serve the same communicative 
functions as the source text (Nord, 2002, p. 43). The literal technique is adopted in Chinese official slogan translation on the condition that the source slogan and the corresponding literal version have the similar designative and pragmatic meanings, for its corresponding expression in the target language can achieve the same informative, appellative, and referential functions of the original slogan.

In some cases, a literal or nearly literal rendering without violating either intertextual or intratextual coherence may successfully fulfill the intended communicative purpose. Therefore, the translators do not have to bother to find other expressions. Literal translation is preferable whenever the referential, appellative, and referential functions can all thereby be achieved.

Judging from the above discussion, we may safely say that literal translation has its advantages and is worth employing in the Chinese official slogan translation. To be sure, translators are not always so fortunate. Besides, using the literal method also poses problems in the process of translation, such as incompatibility between the form of the translated version and the content of the slogan, ambiguity caused by different characteristics of the two languages and cultures involved in translation, and the elusive meaning of the culturally-loaded words. As a result, more often than not, translators have to make changes to the original slogans in terms of form or content. This is the so-called liberal translation, which the authors have mentioned in the previous section.

It is also evident that Chinese official slogans should not be translated in isolated situations. Proper explanation of the context and sufficient background information is needed for understanding the meaning of slogans. Many are abbreviations of longer political statements. Such abbreviations omit information that might be gained through other means of communication, such as, mass media within mainland China. For readers from English-speaking countries who are not exposed to the media broadcasting of the unabbreviated statements, it is unlikely to understand the meanings of the omissions. Slogans such as "One country, two systems" (S8), "One central task and two basic points" (S12), "the four cardinal principles" (S1), "the four modernizations" (S2), "three Favorables" (S18), and "eight honors and eight disgraces” (S50) all have numbers in them and fall into this category. For the slogan "not to devalue the RMB" (S24), out of the nine subjects to whom the slogan made no sense, seven mentioned that they did not know what "RMB" stood for. Therefore, the authors suggest changing it to "not to devalue the Chinese Yuan (Chinese currency)". The information in the parenthesis can help readers understand what Yuan means.

\section{Linguistic Differences and Corresponding Solution}

Finally, language itself is responsible for many misunderstandings of Chinese official slogans. Since some translators did not pay enough attention to linguistic and rhetoric differences, many respondents find some slogans vague, illogical, and inaccurate in the choice of words, and ungrammatical.

The major problem in S43 is the word "rejuvenation" in the second version ("National rejuvenation through science and education”). One respondent said that this word "makes China sound like it's behind" (personal communication, September 9, 2008). Others thought that "rule by law" (S44) sounded "oppressive" or that it "seems more harsh". One of the most confusing slogans, "five stresses, four points of beauty and three loves” (S6) also has the problem of bad choice of words. Some mentioned that "'stress' is a bad thing. Perhaps they mean to say 'emphasis-es"” (personal communication, September 9, 2008). Others think that "three loves” reminded them of love affairs. Thirty-nine percent people suggested that "Three Favorables” (S18) should be changed into 
“Three favorites". Of those who could not understand "Three Represents” (S25), 23\% believed that it was an incorrect choice of words since "English would not use 'represent' as a noun'”, and "representatives” or "representations" should be used instead. Fourteen percent people pointed out that the word "lofty" in the slogan "Citizens with lofty ideals, moral integrity, better education and good sense of discipline” (S5) was not used appropriately. Some said that " 'lofty' doesn't seem to fit with the rest of the sentence, since I think of 'unrealistic' when I see the word 'lofty”” (personal communication, September 11, 2008). "Higher-ideals” sounded more colloquial and more like English. When it came to the slogan "Arming people with scientific theory, guiding people with correct media, figuring people with high-minded spirit, inspiring people with excellent works" (S20), $16 \%$ of the respondents held that "figuring people with" did not make any sense, since "we cannot 'figure' a person". Nine percent thought that "high-minded spirit” sounded "peculiar”, and "does not make sense at all”. The translation that caused most controversy in terms of sentence structure was "The intensive education in the need to stress study, political awareness and integrity" (S23). Some thought that it was an incorrect sentence and that "the first part of the sentence is hard to understand due to the incorrect grammar"; one used the words "a bit verbose" to state his/her impression of this slogan; another said that "I can't tell if the intensive education is to study these things because of the grammar" (personal communication, September 9, 2008). Some thought that putting "the" at beginning of sentence was grammatically incorrect. Also, "intensive education to stress study" made no sense, since "education and study are the same things".

Some respondents did not express a definite choice when asked about their preferences. For instance, slogan 47 was designed more like a choice between "Musts" and "Necessities". Twenty-five percent of the respondents made no choice, stating that they needed more context to understand this slogan fully. For the three versions of S48 (“People-oriented”, "People first”, and “"Putting people first' principle”), 13\% expressed more than one choice, some indicating that they chose more than one because they did not see any difference, while others chose none, because they all meant different things. Similarly, for the three versions of S49 ("To build an energy-saving society", "to build a conservation-oriented society”, and "to build an economized society"), 14\% expressed either more than one choice or none at all. Their reason was that "energy", "conservation”, and "economy” were three different concepts. As for the slogan "Time is money, efficiency is life" (S9), many a respondent found it hard to accept because they perceived no direct relationship between these two statements. How come efficiency is life? How does it relate to "Time is money"? Therefore, some subjects suggested that it would be more acceptable if the sentence were rephrased "Time is money, time is efficiency" or "Time is money, money is life". Some thought that there was no logical relationship in the slogans "Seeking truth from facts, liberation of mind" (S3), "reform and opening up" (S4), and "One central task and two basic points" (S12). In brief, these slogans all lacked logic or did not live up to the respondents' expectations of what good English should be.

As mentioned in the previous section, since Chinese and American cultures share some similarities, many slogans can be literally translated. However, it should be pointed out that literal translation does not necessarily mean word-for-word translation, neither a word more nor a word less in translating Chinese official slogans. Due to the differences between two languages, it is impossible to achieve word-for-word translation in many cases. According to MAO Dun, it would be dead translation if translators mechanically moved the definition into the translation regardless of whether it was well collocated in the target language (LIU, 1996, p. 97). In 
other words, adjustment of the word order is indispensable in doing literal translation so that the version can be in accordance with the target readers' linguistic inventions. The following versions are rendered by adjusting the word order of the original slogan: "To build a well-off society in an all-round way" (S28), "Gear education to the needs of modernization, the world and the future" (S39), and "Revitalizing China through science and education" (S43). They conform to the linguistic rules of the target language, and thus are more apt to achieve the communicative function and Skopos of the slogans.

On the other hand, literal translation alone is not a perfect solution to slogan translation. In many cases, liberal translation is preferable, because differences between Chinese and English are more significant than the similarities. In the process of Chinese-English translation, these differences will hinder correctly translating or even produce "Chinglish”, i.e., phrases or sentences in Chinese structures with English words. Obviously, such versions can never live up to the expectations of target readers. They may find them strange and hard to accept. Therefore, in the process of translation, we must often adopt liberal translation so as to retain the informative, appellative, and referential functions of the original slogans.

Chinese is a language centering on the cohesion of meaning as the whole that permits many omissions, while English emphasizes clear logical relationships between words. As a consequence, we must add some words in the process of Chinese-English translation. Take the slogan "Cadres are more revolutionary, younger, better-educated and more professional” (S38) as an example. At first glance, this is a slogan that consists of four parallel three-character words, all ending with the word hua [corresponding for English prefix "-ize”]. But this slogan poses a great problem to translators. Some might say that the prefix “-ize”, which is usually added after adjectives and nouns, such as normalize, systematize, and rationalize can be used here. However, even though the word "modernize" exists, we cannot find corresponding words for the rest. Coining words like "youngize"or "knowledgize" would only cause confusion to foreigners, who may think it a slogan with spelling mistakes.

Actually, the implied meaning of the slogan is that the selection and training of cadres of CPC is not going on a reform, but rather should be more like this. There is a sense of comparative degree in the original slogan. With so much information to give, here the translation technique of liberal translation had better be employed. Professor DING (2001) proposed this version: "The contingent of cadres should be composed of staunch revolutionaries who are better educated, better trained and younger in age” (p. 26). Obviously, his version differs from the original slogan in both form and content. In terms of form, the original parallel structure is nowhere to be found; in terms of content, it is enhanced in order to give the target readers clearer and more detailed information.

Another example is the slogan "One family, one child" (S37). Variations of it are "You had better have only one child!”, "It is good to have only one child”, and "one family, one child”. The first two are literal translations and the last one is a liberal translation. The first version appeared on a banner in a big city center several years ago. Upon seeing this, some Western tourists were shocked. They thought that the Chinese authorities were threatening the people. It turned out that the phrase "had better" has a meaning of warning that if you do not do something, we will take some action (CHEN, 2003). Therefore, this literally translated version not only fails to reach the referential and expressive function of the original slogan, but it also causes misunderstanding. The second version uses a common structure "it is good to do something" and seems to comply with an English way of speaking. However, some people think this version will prompt a question: "Why?” The last version, by using 
a parallel structure and adding the word "family", supplies readers with some background information and also makes a vocal impact by repeating the word "one”. Thus, "one family, one child” has become the most favorable version to this day, which can still be found in many newspapers at home and broad.

In order to convey more accurately and fully the true meaning of slogans, translators should give high priority to the conventions and logical features of English. Be precise in the choice of words and modify sentence structures when necessary to present simple, direct, and memorable slogans. For example, "The intensive education in the need to stress study, political awareness and integrity" (S23), which was perceived as ungrammatical, could be revised to "Intensive education is needed to stress study, political awareness and integrity" or "Stress study, political awareness and integrity through intensive education". In this way, mistakes in grammar are avoided, and the sentence will seem more natural to readers. Also, some translations which faithfully convey the meanings of the source texts fail to produce the expected effects for various reasons. In such circumstances, translators should consider other approaches, or having "transformation of the forms".

All in all, fuzziness of language is a common feature of English and Chinese, as both languages depend on social and cultural background. The blanks brought by the fuzzy language for the original readers can be filled in with their existing knowledge. However, such impression, if preserved in a translated text, may become a vacuum or a missing link for readers. Different features of the two languages can also cause confusion. For slogan translation, it is particularly essential that we respect the features of the target language and make the translated text comply with its logic and ways of expression. Only in this way can translated slogans fulfill their communicative functions and be accepted by native speakers.

\section{Conclusions}

Our analysis of the questionnaires and subsequent interviews has led to the following conclusions: We believe that the translation of Chinese slogans should be practiced on a basic standard of acceptability, that is, the translation should effectively serve the Skoposi, or purposes, of Chinese official slogans. After all, the fundamental purpose is to promote foreigners' understanding of China and help to project to the world a developing and progressive national image. In order to achieve this, the translation of slogans should be guided by three principles: faithfulness, comprehensiveness, and linguistic accuracy and modification.

Faithfulness: The premise of acceptability in slogan translation is to grasp the essence of the slogans and make sure that the translations faithfully convey the intended information. Nord (2002) had put forward the "Loyalty Principle” as a complement to the Skopostheorie, namely, that translators should respect the source-text producer and coordinate the translation purpose with his ot her intention. In the practice of translating Chinese official slogans, it is of supreme importance that translators have a thorough understanding of the slogans and see that all the indispensable information is conveyed.

Comprehensiveness: Based on the standard of faithfulness, translators should be fully aware of the target readers' lack of contextual knowledge and provide essential information about the slogans. In other words, the translations should not appear in isolated situations. Instead, adequate explanations and sufficient background information for the slogans should be provided to help readers understand their meaning. As the second rule of Skopostheorie emphasizes, a translation should be acceptable in a sense that it is coherent with the receivers' 
situation. For target-receivers who lack sufficient cultural knowledge of China, translators should produce a comprehensive text that is meaningful to them.

Accuracy and modification: This principle should be based on the previous two. In order to convey more accurately and fully the true meaning of the slogans, translators should give high priority to the conventions and logical features of English. Be precise in the choice of words and modify sentence structures as much as necessary to present a simple, direct, and memorable slogan. At the same time, try to preserve such features as parallelisms and rhyme. In this process, the translation strategies of literal translation, liberal translation, and a combination of the two are all very useful. Since foreign publicity and readers' reception are of considerable importance in Chinese official slogan translation, all the strategies are indispensable and can complement each other. None is the sole and universal strategy. When one strategy does not work owing to linguistic, customary, cultural, or other factors, naturally the translators must turn to others. They should have a better understanding of the essence of each strategy and make the best use of them in a flexible and realistic way.

\section{References}

CHEN, B. Y. (2003). 旅游英语及其翻译 (Tourism English and its translation). Journal of Zhejiang Shuren University, (4), 55-57, 85.

CHEN, X. W. (2007). 外宣标语口号译文建构的语用修辞分析 (Pragmatic rhetorical analysis of the Chinese slogan translation) Journal of Fuzhou University (Philosophy and Social Sciences), (1), 94-99.

DING, H. Q. (2001). 汉英英汉翻译的“特效处理” (“Special Effect Approach” in Chinese-English and English-Chinese Translation). Chinese Translators Journal, (6), 23-27.

DING, M. A. (1999). 宣传口号的英语翻译 (English translations of Chinese slogans). Shanghai Journal of Translators for Science and Technology, (1), 26-27.

FEI, H. (2006). 英语新词的社会文化透视 (A social and cultural perspective on newly coined English words). Journal of Kunming University of Science and Technology (Social Sciences), (4), 68-72.

LIU, F. (1996). 提高对外宣传品汉译英质量的几点思考 (A few thoughts on promoting the Chinese-English translation quality in foreign publicity). Journal of Qinghai Normal University (Social Sciences), (3), 96-99.

LIU, F. G. (1995). 试评我国经贸领域汉英翻译的现状 (Comment on the status quo of Chinese-English translation in China’s economy \& foreign trade). Foreign Languages and Their Teaching, (3), 44-47.

LIU, Z. D. (1995). 文学翻译十讲 (Ten talks on literature translation). Beijing: China Translation and Publishing Company.

LU, Z. B. (1994). 从翻译技巧看汉语标语的翻译 (Reflection on the translation of Chinese slogans from the perspective of translation skills). Journal of Xi'an International Studies University, (1), 51-56.

LUO, T. F. (1999). 标语文本汉译英转换中语言和文化差异的处理 (How to deal with linguistic and cultural differences in slogan translation from Chinese into English). Shandong Foreign Language Teaching Journal, (2), 56-59.

Malmkjear, K. (2004). Translation in undergraduate degree programmes. Amsterdam: John Benjamins Publishing Co..

MAO, D. H. (2004). 从政治时事术语的翻译看中国英语 (On “Chinglish” in the translation of political terms). Journal of Ningbo Radio \& TV University, (3).

Nord, C. (2002). Translation as a purposeful action. Shanghai: Shanghai Foreign Language Education Press.

Pochhacker, F. (1995). “Those who do...”: A profile of research(ers) in interpreting. Target, 7(1), 17-24.

Reiss, K., \& Vermeer, H. J. (1984). Grundlegung einer allgemeinen Translationstheorie. Niemeyer: Niemeyer.

SHEN, C. H., \& LIU, J. X. (2000). 标语英译浅谈 (On translation of slogan from English into Chinese). Journal of Wuhan Polytechnic University, (1), 81-83.

SHI, X. L. (2004). 谈中文标语英译的对等问题 (On the equivalence of slogan translation from Chinese into English). Journal of Xianning College, (2), 152-154. 
TANG, Y. F. (2000). 从一则标语的误译说起一浅析汉语标语的英译 (On translating Chinese slogans into English). Journal of Jishou University (Social Science Edition), (2), 64-66.

Vermeer, H. J. (1989). Skopos and commission in translational action. In A. Chesterman (Ed.), Readings in translation. Helsinki: Oy Finn Lectura Ab.

WU, D. L., \& ZHANG, B. (2007). 中美思维方式在政治口号上的体现与对比 (The reflection and comparison in the mode of thinking between China and America). Journal of Changchun Normal University (Humanities and Social Sciences), (1), 106-108.

WU, W. X. (1998). 中文标语英译浅谈 (On translation of Chinese slogans into English). Chinese Translators Journal, (1), 35-38.

WU, W. X. (2006). 跳出标语译标语, 现场见效最相宜一中文标语英译的语句特点与现场效果 (On the sentence style and situational effect in English translation from Chinese slogans). Shanghai Journal of Translators, (2), 30-34.

YANG, Y. (2006). 关于有中国特色的政治经济词汇的英译 (On English translation of political \& economic words and phrases with Chinese characteristics). Journal of Shaoyang University (Social Sciences), (2), 103-105, 116.

YU, C. F. (2002). 中文标语的变译策略一从“新北京 新奥运” 谈起 (On the strategy of variation in translating Chinese slogans). Journal of Shayang Teachers College, (4), 51-54.

ZHU, Y. Q. (2006). 标语英翻译可接受性问题探讨 (On the acceptability of English translation of Chinese slogans). Journal of South China Normal University (Social Science Edition), (6), 60-66. 